\title{
Therapeutic potential of inhibition of the NF- $\kappa B$ pathway in the treatment of inflammation and cancer
}

\author{
Yumi Yamamoto and Richard B. Gaynor \\ Division of Hematology-Oncology, Department of M edicine, Harold Simmons Cancer Center, \\ University of Texas Southwestern M edical Center, Dallas, Texas, USA \\ Address correspondence to: Richard B. Gaynor, Division of H ematology-O ncology, D epartment of M edicine, \\ University of Texas Southwestern M edical Center, $5323 \mathrm{H}$ arry H ines Boulevard, Dallas, Texas 75390-8594, USA. \\ Phone: (214) 648-4996; Fax: (214) 648-4152; E-mail: gaynor@utsw.swmed.edu.
}

NF-kB comprises a family of inducible transcription factors that serve as important regulators of the host immune and inflammatory response. In addition, NF- $\mathrm{kB}$ is also involved in protecting cells from undergoing apoptosis in response to DNA damage or cytokinetreatment. Stimulation of the NF-kB pathway is mediated by diverse signal transduction cascades. These signals activate the I $\mathrm{KB}$ kinases, IKK $\alpha$ and IKK $\beta$, which phosphorylateinhibitory proteins known as I $\mathrm{KB}$ to result in their ubiquitination and degradation by the proteasome. The degradation of $I \kappa B$ results in the translocation of NF-KB from the cytoplasm to the nucleus whereit activates the expression of specific cellular genes. As we better understand the regulation of the NF-KB pathway, the potential for inhibiting this path way has received attention. Agents that inhibit this pathway, such as glucocorticoids and aspirin, can reduce the inflammatory response, while other agents such as dominant negative $\mathrm{\kappa B}$ proteins potentiatethe effects of chemotherapy and radiation therapy in the treatment of cancer. Here, we discuss cellular genes and disease states associated with activation of the N F-KB pathway and consider therapeutic strategies to prevent the prolonged activation of the N F-кB pathway.

\section{$\mathrm{NF}=\kappa \mathrm{KB}$ activation of cellular genes involved in the immune and inflammatory response}

NF- $\mathrm{KB}$ regulates host inflammatory and immune responses (1-4) and cellular growth properties (5) by increasing the expression of specific cellular genes. These include genes encoding at least 27 different cytokines and chemokines, receptors involved in immune recognition such as members of the $\mathrm{MHC}$, proteins involved in antigen presentation, and receptors required for neutrophil adhesion and migration (2). Cytokines that arestimulated by N F- $\mathrm{kB}$, such as IL$1 \beta$ and TNF- $\alpha$, can also directly activate the NF- $\kappa B$ pathway, thus establishing a positive autoregulatory loop that can amplify the inflammatory response and increase the duration of chronic inflammation.

$\mathrm{NF}-\mathrm{kB}$ also stimulates the expression of enzymes whose products contribute to the pathogenesis of the inflammatory process, including theinducibleform of nitric oxide synthase (iNOS), which generates nitric oxide (NO), and theinducible cyclooxygenase (COX-2), which generates prostanoids (2). The N F-kB pathway is likewise important in the control of the immune response. It modulates B-lymphocyte survival, mitogen-dependent cell proliferation, and isotype switching, which lead to the differentiation of B lymphocytes into plasma cells (3). In addition, N F-KB regulates IL-2 production, which increases the proliferation and differentiation of $T$ lymphocytes $(2,3)$. Thus, activation of $\mathrm{NF}-\mathrm{kB}$ leads to the induction of multiple genes that regulate the immune and the inflammatory response.

\section{$\mathrm{NF}=\mathrm{KB}$ regulation of cellular apoptosis and proliferation}

In addition to activating the expression of genes involved in the control of the immune and inflammatory response, the NF- $\kappa$ B pathway is al so a key mediator of genes involved in the control of the cellular proliferation and apoptosis (5). Antiapoptotic genes that are directly activated by NF-kB include the cellular inhibitors of apoptosis (C-IAP1, C-IAP2, and IXAP), the TN $F$ receptor-associated factors (TRAF1 and TRAF 2 ), the BCl-2 homologue A1/Bfl-1, and IEX-IL $(6,7)$.

One of the best-studied pathways that activates apoptosis is induced following treatment of cells with TN F- $\alpha$. TNF $-\alpha$ treatment increases the expression of TRAF1, TRAF2, C-IAP1, and C-IAP2 (6). The overexpression of these proteins can protect RelA-deficient cells, which are highly sensitive to TNF- $\alpha$-induced apoptosis, from cell death. These antiapoptotic proteins block theactivation of caspase-8, an initiator protease, involved at an early step in stimulating the apoptotic pathway (6).

$\mathrm{M}$ embers of the $\mathrm{Bcl}-2$ family may be antiapoptotic, as is thecasewith $\mathrm{BCl}-2, \mathrm{BCl}-\mathrm{xL}$, and $\mathrm{A} 1 / \mathrm{Bfl}-1$, or proapoptotic, as with Bad, Bax, and Bcl-xS. NF-kB directly induces expression of $A 1 / B f 1-1$ by binding to specific sites in its promoter (8). Theconstitutive expression of $\mathrm{A} 1 / \mathrm{Bfl}-1$ inhibits antigen receptor-induced apoptosis in B lymphocytes derived from c-Rel-deficient mice,

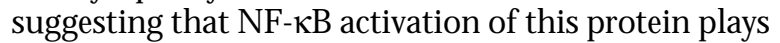
an important rolein theB lymphocyte survival follow- 
ing lymphocyte activation (8). The chemotherapeutic agent etoposide also increases N F-KB levels and thereby induces $A 1 / B f l-1$, which prevents cytochrome $C$ release from mitochondria and activation of caspase-3 (9). By increasing the expression of antiapoptotic cellular proteins, N F- $\mathrm{kB}$ activation can thus reduce apoptosis in response to treatment with different chemotherapeutic agents.

$N F-\kappa B$ also acts in the control of the cell cycle, which is a critical element in determining the degree of celluIar apoptosis and proliferation. N F-KB activates the expression of cyclin D1, a positive regulator of G1-toS-phase progression, by direct binding to multiplesites in its promoter (10). Inhibition of NF-kB activation can reduce cycl in D 1 activity and subsequent phosphorylation of the retinoblastoma protein to result in delayed cell cycle progression. This impaired cell cycle progression can be rescued by ectopic expression of cyclin D1 (11). Thus, the suppression of apoptosis induced by NF-KB involves the regulation of multiple genes involved in different aspects of growth control.

Role of $N F=K B$ in pathogenesis of human disease

Activation of the NF-KB pathway is involved in the pathogenesis of chronic inflammatory diseases, such as asthma, rheumatoid arthritis (see Tak and Firestein, this Perspectiveseries, ref. 12), and inflammatory bowel disease. In addition, al tered N F- $\mathrm{KB}$ regulation may be involved in other diseases such as atherosclerosis (see Collins and Cybulsky, this series, ref. 13) and Alzheimer's disease (seeM attson and Camandola, this series, ref. 14), in which the inflammatory response is at least partially involved. Finally, abnormal ities in the NF-kB pathway are also frequently seen in a variety of human cancers.

Several lines of evidence suggest that N F-kB activation of cytokine genes is an important contributor to the pathogenesis of asthma, which is characterized by the infiltration of inflammatorycells and the dysregulation of many cytokines and chemokines in the lung (15). Likewise, activation of the N F-KB pathway also likely plays a rolein the pathogenesis of rheumatoid arthritis. Cytokines, such as TNF- $\alpha$, that activate NF-kB are ele vated in thesynovial fluid of patients with rheumatoid arthritis and contribute to the chronic inflammatory changes and synovial hyperplasia seen in the joints of these patients (16). The administration of antibodies directed against TNF- $\alpha$ or a truncated TNF- $\alpha$ receptor that binds to TN F- $\alpha$ can markedly improve the symptoms of patients with rheumatoid arthritis.

Increases in the production of proinflammatory cytokines by both lymphocytes and macrophages has also been implicated in the pathogenesis of inflammatory bowel diseases, including Crohn's disease and ulcerative colitis (17). NF- $\mathrm{KB}$ activation is seen in mucosal biopsy specimens from patients with active Crohn's disease and ulcerative colitis. Treatment of patients with inflammatory bowel diseases with steroids decreases NF- $\kappa$ B activity in biopsy specimens and reduces clinical symptoms. These results suggest that stimulation of the NF-אB pathway may be involved in the enhanced inflammatory response associated with these diseases.

Atherosclerosis is triggered by numerousinsults to the endothelium and smooth muscleof thedamaged vessel wall (18). A large number of growth factors, cytokines, and chemokines released from endothelial cells, smooth muscle, macrophages, and lymphocytes are involved in this chronic inflammatory and fibroproliferativeprocess (18). NF-KB regulation of genes involved in the inflammatory responseand in thecontrol of cellular proliferation likely plays an important rolein theinitiation and progression of atherosclerosis.

Finally, abnormal ities in the regulation of theN F-kB pathway may be involved in the pathogenesis of Alzheimer's disease. For example, NF-kB immunoreactivity is found predominantly in and around early neuritic plaque types in Alzheimer's disease, whereas mature plaque types show vastly reduced NF- $\kappa B$ activity (19). Thus, NF-KB activation may beinvolved in the initiation of neuritic plaques and neuronal apoptosis during the early phases of Alzheimer's disease. These data suggest that activation of the N F- $\kappa B$ pathway may play a rolein a number of diseases that have an inflammatory component involved in their pathogenesis.

In addition to a role in the pathogenesis of diseases characterized by increases in the host immune and inflammatory response, constitutive activation of the NF-kB pathway has al so been implicated in the pathogenesis of some human cancers. Abnormalities in the regulation of the NF-KB pathway arefrequently seen in a variety of human malignancies including leukemias, lymphomas, and solid tumors (20). These abnormalities result in constitutively high levels of NF- $\mathrm{KB}$ in the nucleus of a variety of tumors including breast, ovarian, prostate, and colon cancers. The majority of these changes arelikely due to alterations in regulatory proteins that activatesignaling path ways that lead to activation of the NF-KB pathway. H owever, mutations that inactivate the $\mathrm{KB}$ proteins in addition to amplification and rearrangements of genes encoding NF-KB family members can result in the enhanced nuclear levels of $\mathrm{NF}-\mathrm{KB}$ seen in sometumors.

Potential targets for inhibiting the $\mathrm{NF}-\kappa \mathrm{B}$ pathway Activation of the NF- $\mathrm{kB}$ pathway requires a number of discrete steps. It is important to review this pathway in order to better understand how different agents can prevent theactivation of this pathway. TheN F-kB proteins comprise a family of proteins that share a 300-amino acid domain that is designated the Rel homology domain $(1,4)$. The Rel homology domain mediates the DN A binding, dimerization, and nuclear

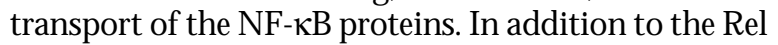


homology domain, the NF-kB family members c-Rel, RelB, and $p 65$ also contain a transactivation domain. The N F-kB family members $\mathrm{p} 50$ and p52, which are derived from the inactive precursors p105 and p100, respectively, possess DNA binding and dimerization properties but not strong transactivation domains. It is the differential expression of these proteins, their ability to heterodimerizewith different family members, and theinteraction of these proteins with different components of thetranscription apparatus that contributeto the diverse effects of activating the NF-KB pathway.

In unstimulated cells, NF-KB proteins arelocalized in the cytoplasm, associated with a family of inhibitor proteins known as I $\mathrm{\kappa} B(|\kappa B \alpha,| \kappa B \beta, \mid \kappa B \varepsilon)(1,4)$. The $I \kappa B$ proteins contain several distinct domains, including ankyrin repeats that are critical for $I \kappa B$ interactions with $\mathrm{NF}-\kappa \mathrm{B}$, an $\mathrm{NH}_{2}$-terminal regulatory domain that is a target for the inducible phosphorylation and subsequent ubiquitination of $\mathrm{I} \mathrm{KB}$, and a $\mathrm{COOH}$-terminal PEST domain that is important in regulating $I \kappa B$

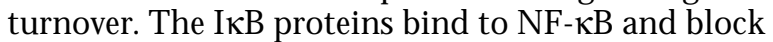
their nuclear localization signal. A variety of stimuli including cytokines such as TN F- $\alpha$ and IL-1, phorbol esters, LPS, viral infection, the human T-cell leukemia virus type 1-transforming protein Tax, ultraviolet radiation, and freeradical s result in the degradation of $I \kappa B$ and the nuclear translocation of N F- $\mathrm{kB}(2)$.

The phosphorylation of the I $\mathrm{KB}$ proteins is a key step involved in the regulation of Rel/NF- $\mathrm{kB}$ complexes. The phosphorylation of the $I \kappa B$ proteins is mediated by I $\kappa B$ kinases (IKKs) (21), whose activity is strongly induced by activators of the NF- $\mathrm{KB}$ pathway $(1,4)$. IKK activity is present in a high-molecularweight complex containing at least two kinase subunits, IKK $\alpha$ and IKK $\beta$, and the associated modulatory protein, IKK $\gamma$ or NEM O (21). The IKKs have $52 \%$ amino acid identity and a similar structural organization, which includes kinase, leucinezipper, and helixloop-helix domains. These kinases are able to form both homo- and heterodimers. Biochemical analysis and gene disruption studies of the IKK genes in mice indicate that IKK $\beta$ is the critical kinase involved in activating the N $\mathrm{F}-\mathrm{KB}$ pathway, while I KK $\alpha$ likely plays an accessory role (21). However, both IKK $\alpha$ and IKK $\beta$ are essential genes for mouse viability. The activated IKK complex phosphorylates the I $\kappa B$ proteins on two closely spaced serine residues in the amino terminus of these proteins $(1,4)$. Phosphorylation of I $\kappa B$ leads to its ubiquitination on two amino-terminal lysine residues by the $\mathrm{E} 3$ ubiquitin ligase complex, thus targeting it for degradation by the 265 proteasome (21). Freed of their association with the $\mathrm{kB}$ subunits, the $\mathrm{NF}-\mathrm{kB}$ proteins translocateto thenucleus, wherethey bind to specific elements in the promoter regions of target genes to activate gene expression.

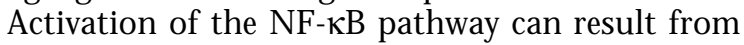
stimulation by a variety of different signal transduction pathways. Although IKK is a key regulator of the NF$\kappa B$ pathway, ubiquitination of $I \kappa B$ and its subsequent degradation by the proteasome are also required for $\mathrm{NF}-\mathrm{kB}$ activation. Furthermore, the differential nuclear translocation of members of theN F- $\mathrm{kB}$ family and the specific phosphorylation of these proteins are also involved in the ability of the N F-KB proteins to activate gene expression. Given the diverse processes involved in activating the NF-KB pathway, it is not surprising that a number of different inhibitors can prevent activation of this pathway. In the following sections, we discuss the mechanisms by which theseinhibitors alter theNF-kB pathway in inflammatory states and cancer.

\section{Inhibition of the $\mathrm{NF}-\mathrm{KB}$ pathway using}

degradation-resistant $\|_{K} B$ proteins

The first evidence that the NF-KB pathway could be specifically inhibited came from studies of $1 \kappa B \alpha$ mutants $(1,4)$. Signal-induced phosphorylation and degradation of cytoplasmic $I \kappa B \alpha$ is required for N F- $\kappa B$ pathway activation. However, an $I \kappa B \alpha$ protein with mutations at serine residues 32 and 36 is not subject to phosphorylation by IKK and is not degraded by the proteasome. This I $\mathrm{kB} \alpha$ mutant or super-repressor has a dominant negative phenotype because it sequesters NF-KB in the cytoplasm and thus prevents the induction of specific NF- $\kappa B$ target genes.

Blocking the NF- $\kappa B$ pathway by the $I \kappa B \alpha$ superrepressor enhances the sensitivity of cells to apoptosisinducing stimuli. For example, TNF- $\alpha$ treatment of cells induces theNF- $\mathrm{kB}$ pathway and results in cellular apoptosis $(22,23)$. SinceN F- $k B$ protects cells from undergoing apoptosis, blocking this path way enhances apoptosis. The expression of the $I \kappa B \alpha$ super-repressor enhances sensitivity to TNF- $\alpha$-induced apoptosis in Jurkat cells, which are otherwise relatively resistant to apoptosis $(22,23)$. Themigration of phosphatidylserine from theinner to the outer leaflet of plasma membrane, which is an early event in apoptosis, is also markedly increased in TN F- $\alpha$-treated Jurkat cells expressing the IкB $\alpha$ super-repressor (23). The expression of this I $\mathrm{\kappa B} \alpha$ protein in the human fibrosarcoma cells also en hances their sensitivity to apoptotic killing by ionizing radiation or thechemotherapeutic agent daunorubicin, each of which are able to activate the N F-кB pathway (22). In contrast, the I $\mathrm{\kappa B} \alpha$ super-repressor does not have any effect on preventing apoptosis induced by the kinase inhibitor staurosporine, which induces cell death in an $\mathrm{NF}-\mathrm{kB}$-independent manner. These results indicate that the $1 \kappa B \alpha$ super-repressor can enhance cell killing by blocking the N F-kB pathway.

Theadenoviral delivery of the IкB $\alpha$ super-repressor to chemoresistant tumors in mice sensitizes these cells to undergo apoptosis in response to treatment with either TN F- $\alpha$ or the chemotherapeutic agent CPT-11, resulting in tumor regression (ref. 24; see also Baldwin, this Perspectiveseries, ref. 25). The IкB $\alpha$ super-repressor al so 
suppresses constitutive and TNF- $\alpha$-induced NF-KB activity in human head and neck carcinoma cells in tissue culture and reduces the growth of such tumors in SCID mice (24). These results suggest that the I $\mathrm{kB} \alpha$ super-repressor inhibits the expression of NF$\kappa \mathrm{B}$-dependent genes, which can enhancethegrowth of squamous cell carcinomas. Thus, NF-kB has an important rolein the regulation of cellular proliferation, and inhibition of the NF-KB pathway may enhancethe efficacy of cancer chemotherapy.

\section{D iverse mechanisms involved in glucocorticoid- mediated repression of the NF-KB pathway}

Glucocorticoids, such as dexamethasone and prednisone, are widely used for their anti-inflammatory and immunosuppressive properties. These agents interact with thesteroid receptor to downregulatethe expression of specific genes that regulate the inflammatory process. There are several proposed mechanisms to explain the inhibitory effects of glucocorticoids on the NF-KB pathway.

The first mechanism is consistent with a role for glucocorticoids in inducing expression of $\mathrm{I} \kappa \mathrm{K} \alpha$ to enhance the cytosolic retention of NF-KB $(26,27)$. D examethasoneinduces the synthesis of $I \kappa B \alpha$ mRN A in glucocorticoid receptor-expressing Jurkat cells (26) and in monocytic cells (27), increasing the level of $I \kappa B \alpha$ and resulting in the cytoplasmic retention of p65. The majority of newly synthesized $I \kappa B \alpha$ induced by dexamethasoneis associated with p65 in pre-existing N F- $\kappa B$ complexes (27). Glucocorticoid-mediated inhibition of NF-KB DNA binding is blocked by the addition of cycloheximide, an inhibitor of protein synthesis. Taken together, these results demonstrate that the rapid degradation of $\mathrm{I} \kappa \mathrm{B} \alpha$ protein seen in response to either TNF- $\alpha$ or phorbol ester treatment of cells can be compensated by dexamethasoneinduced synthesis of I $\mathrm{\kappa B} \alpha$. NF- $\mathrm{KB}$ is thus maintained in an inactive cytoplasmic complex so that the expression of genes involved in the pathogenesis of the immune response is reduced.

However, other mechanisms are al so likely involved in glucocorticoid-mediated repression of the N F-KB pathway. For example, dexamethasone can repress IL6 expression and p65-dependent transactivation in murine endothelial fibroblasts without changing $I \kappa B$ protein levels or NF-KB DNA-binding activity (28). Similarly, in primary endothelial cells, dexamethasone reduces $\mathrm{NF}-\mathrm{KB}$-mediated transcriptional activity without altering $I \kappa B$ protein levels or the nuclear transl ocation of NF-KB. These results indicate that in certain cell types the downmodulation of NF$\kappa \mathrm{B}$-directed geneexpression by glucocorticoids is due to other mechanisms. For example, direct protein-protein interactions between the activated glucocorticoid receptor and NF-kB can also prevent activation of this pathway $(28,29)$. Protein crosslinking and coim- munoprecipitation studies demonstrate a physical association between the activated glucocorticoid receptor and the $\mathrm{p} 65$ subunit of NF-kB.

Competition between NF- $\mathrm{kB}$ and the glucocorticoid receptor for limiting amounts of the coactivators CREB-binding protein (CBP) and steroid receptor coactivator-1 (SRC-1) has al so been proposed to explain glucocorticoid-mediated inhibition of NF-KB (30). These coactivators bind to both p65 and the glucocorticoid receptor and are critical for the transactivation properties of both of these proteins. Cotransfection assays demonstratethat the expression of increasing amounts of coactivators counteracts glucocorticoid-mediated repression of the N F-KB pathway. These results implicate coactivators in the antagonistic interaction between theglucocorticoid receptor and p65. However, a recent study demonstrates that glucocorticoid-mediated repression of NF-kB activity occurs irrespective of coactivator levels (31), suggesting that glucocorticoid repression of p65 transactivation is specifically determined by thecontext of theTATA box relative to the $\kappa B$ binding sites in different promoters. Thus, it is possible that the glucocorticoid receptor directly disrupts p65 interactions with the basal transcription machinery, by direct interactions either with $\mathrm{p} 65$ or with components of the basal transcription complex.

\section{N onstero idal anti-inflammatory drugs and IKK activity}

Nonsteroidal anti-inflammatory drugs (N SAIDs) are widely used in the treatment of chronic inflammatory states. In addition, theseagents inducetheregression of adenomatous polyps of the colon and prevent the development of colon cancer. The most commonly accepted theory to account for the inhibitory effects of these agents on the inflammatory response and the prevention of colon cancer holds that NSAIDs inhibit COX activity to prevent prostaglandin synthesis (32). However, other reports suggest that additional mechanisms are involved in the actions of these agents (33-35).

Aspirin and sodium salicylate are examples of antiinflammatory agents for which the molecular target is, at least in part, NF- $\mathrm{KB}$. At concentrations measured in the serum of patients treated with these agents for chronic inflammatory conditions, both aspirin and salicylate inhibit activation of the NF- $\mathrm{KB}$ pathway (33-35). Theseagents suppress TN F- $\alpha$-induced mRNA synthesis of adhesion molecules and surfaceexpression of VCAM-1 and ICAM - 1 in endothelial cells (33). This inhibition of the N F-KB pathway in endothelial cells prevents transendothelial migration of neutrophils, suggesting that the clinical importance of high-dose salicylates as anti-inf lammatory agents is at least partially due to blocking NF-KB activation to inhibit leukocyte recruitment (33).

Recently, Yin et al. found that theinhibitory effects of aspirin and sodium salicylate result from the specific 
inhibition of ATP-binding to IKK $\beta$ (34). Thus, IKK $\beta$ dependent phosphorylation of $1 \kappa \mathrm{B} \alpha$ is markedly reduced, preventing its degradation by the proteasome and activation of the NF-кB pathway. In contrast, concentrations of indomethacin that inhibit COX activity and result in potent anti-inflammatory responses do not prevent activation of the N F-KB pathway $(33,34)$. Hence, the effects of aspirin and sodium salicylate on inhibiting the NF-KB pathway appear to beindependent of their ability to block COXs.

Sulfasalazine is an anti-inflammatory agent that is used in themanagement of inflammatory bowel disease and rheumatoid arthritis. It combines a nonsteroidal anti-inflammatory moiety (5-aminosalicylic acid; 5-ASA) and an antibacterial moiety (sulfapyridine). After oral administration, about $70 \%$ of sulfasal azine is degraded by colonic bacteria to 5-ASA and sulfapyridine. Treatment of colonic epithelial cells with sulfasalazine, but not 5-ASA or sulfapyridine, inhibits NF-kB activation induced by treatment with either TNF- $\alpha$, LPS, or phorbol ester (36). Theinhibition of the NF-kB pathway by sulfasalazine is associated with suppression of $1 \kappa B \alpha$ phosphorylation and its subsequent degradation. Although the exact role of sulfapyridine in inhibiting $N F-\kappa B$ remains unclear, sulfasal azine appears to owe part of its therapeutic effect to 5-ASA-mediated suppression of NF-kB activation. Interestingly, a related aminosalicylatederivativewith anti-inflammatory properties, mesalamine, prevents IL-1-mediated stimulation of p65 phosphorylation without inhibiting I $\kappa B \alpha$ degradation (37). Thus, nonsteroidal anti-inflammatory agents may inhibit theNF-KB pathway at multiplesteps.

Sulindac is a nonsteroidal anti-inflammatory agent that is structurally related to indomethacin. In the colon, sulindac is converted by bacteria to the metabolites sulindac sulfide, which blocks prostaglandin synthesis by nonsel ective inhibition of COX-1 and COX-2, and sulindac sulfone, which has no such inhibitory effect. Nevertheless, sulindac and both of these metabolites can inhibit activation of the N F- $\mathrm{kB}$ pathway by inhibiting IKK activity (35). In addition, sulindac and aspirin induce apoptosis in HCT-15 cells, a colon carcinoma cell line that is defective in the generation of prostaglandins (35). Theseresults suggest that inhibition of the NF-kB pathway may be involved in the anti-inflammatory as well as thegrowth inhibitory properties of certain NSAIDs.

\section{Inhibition of the $N \mathrm{~F}=\mathrm{KB}$ pathway by immunosuppressive agents}

Cyclosporin A (CSA) and tacrolimus (FK-506) are immunosuppressive agents used in organ transplantation to prevent graft-versus-host disease. These agents, in a complex with the cellular protein cyclophilin, inhibit the activity of calcineurin, a calcium- and calmodulin-dependent serine/threonine phosphatase, to result in the inhibition of cell activa- tion. Calcineurin is required for activation of thetranscription factor NF-AT, which binds to the IL2 promoter and is critical for regulating IL-2 expression in $T$ lymphocytes. In addition, calcineurin can activate the N F- $\kappa B$ pathway (38). In Jurkat cells, transfection of an expression vector containing a $\mathrm{Ca}^{2+}$-independent calcineurin protein results in increased DNA binding and transactivation by NF-kB. Hence, FK-506 and CsA inhibition of calcineurin activity can prevent N F- $\kappa B$ activation under specific conditions.

FK-506 and CSA act by distinct mechanisms to inhibit the NF-kB pathway (38-41). CsA serves as a noncompetitive inhibitor of the chymotrypsin-likeactivity of the $20 \mathrm{~S}$ proteasome and thus prevents $I \kappa B \alpha$ degradation and activation of the NF-KB pathway. This agent inhibits proteasome activity in vitro and suppresses LPS-induced IKB degradation in murine macrophages by stabilizing theubiquitinated forms of $I \kappa B \alpha(38)$. This finding suggests that a target of CsA in inhibiting the N F-KB pathway is the protease activity of the proteasomerather than kinases or ubiquitin ligases that regulate thesignal-induced phosphorylation and ubiquitination of $I \kappa B$, respectively. Similar results areseen in Jurkat cells, as well as human and mouseprimary $T$ lymphocytes, where CSA interferes with the degradation of I $\kappa B \alpha$ following phorbol-ester and ionomycin stimulation without altering $I \kappa B \alpha$ phosphoryIation (39). The proteolytic processing of the N F-кB precursor $\mathrm{p} 105$, which also requires the $26 \mathrm{~S}$ proteasome complex, is not affected by CSA treatment (40).

FK-506 appears to act by a different mechanism to inhibit the NF-kB pathway (41), specifically blocking translocation of c-Rel from the cytoplasm to the nucle us. FK-506 blocks both antigen receptor-induced and phorbol ester and ionomycin-induced c-Rel nuclear translocation in both B and T cells; neither RelB induction nor p50 expression is altered by FK-506 treatment (41). Furthermore, FK-506 suppresses c-Rel-induced transactivation of the gene for the IL-2 receptor $\alpha$ chain. Coexpression of a constitutively active calcineurin activates expression from this gene, suggesting that a cal cineurin-dependent pathway is involved in c-Rel activation. Thus, a portion of the immunosuppressive effects of FK-506 may result from inhibition of c-Rel translocation to result in decreased expression of both IL-2 and its receptor.

\section{Downregulation of the $\mathrm{NF}=\kappa \mathrm{B}$ pathway by cyclopentenone prostaglandins}

$\mathrm{NF}-\mathrm{KB}$ regulates the expression of a variety of genes involved in theimmuneand inflammatory responses, including COX-2. COX-1 is constitutively expressed in most tissues, whereas COX-2 is an inducible enzyme whose expression is enhanced in response to inflammatory stimuli. COX-2 directs the synthesis of anti-inflammatory cyclopentenone prostaglandins (cyPGs), which are involved in theresolution phase of 
inflammation. CyPG s act as intracellular regulators of inflammatory and immune responses as well as cellular proliferation.

Two roles of cyPGs in regulation of the N F-KB pathway have been proposed $(42,43)$. First, cyPG s have been suggested to exert their anti-inflammatory activity through the activation of PPAR $\gamma$, a member of the nuclear receptor superfamily. 15-deoxy- $\Delta^{12,14}$ prostaglandin $\mathrm{J}_{2}(15 \mathrm{dPG})_{2}$; bioactive prostaglandin $\mathrm{D}_{2}$ metabolite) binds and activates PPAR $\gamma$, and in activated macrophages, $15 \mathrm{dPG}_{2}$ inhibits the expression of gelatinase $B$ and NOS and other NF-kB-regulated genes in a PPAR $\gamma$-dependent manner (42).

Other groups have demonstrated that cyPGs themsel ves can directly inhibit NF-KB activity (43). The cyPG metabolite PGA 1 inhibits TNF- $\alpha$-induced

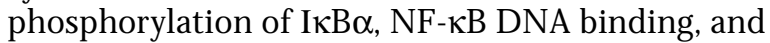
NF-KB transactivation in Jurkat lymphoma cells. A recent study indicates that $P G A_{1}$ and $\left.15 \mathrm{dPG}\right|_{2}$ directly inhibit the IKK $\beta$ activity (43). The inhibition of

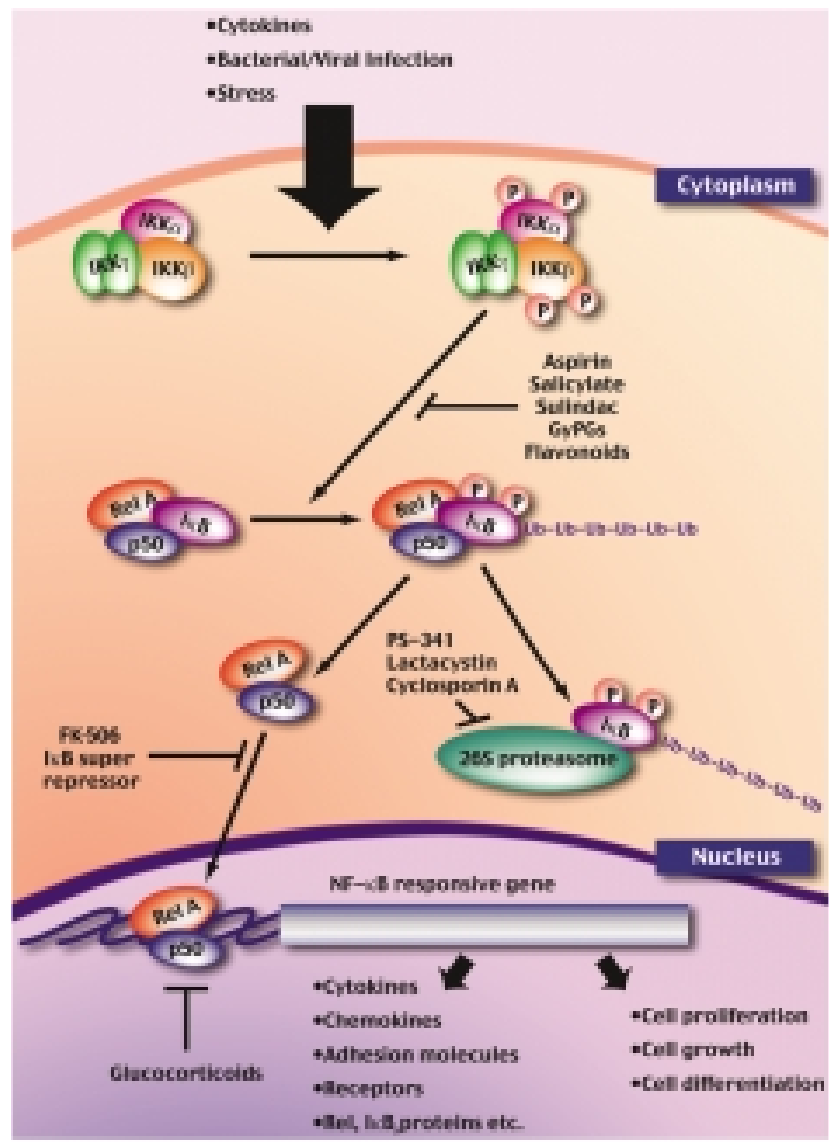

Figure 1

Inhibition of the NF- $\mathrm{KB}$ pathway. A schematic illustrating the steps involved in the activation of the NF- $\mathrm{BB}$ pathway. Numerous drugs, natural products, and normal or recombinant proteins can act at several of these steps to interfere with NF-KB activation.
IKK $\beta$ activity by cyPGs is due to modification of a cysteine residue in the activation loop of IKK $\beta$. As $N F-\kappa B$ regulates COX-2 synthesis, the inhibition of

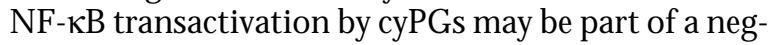
ative feedback loop that contributes to resolution of inflammation.

\section{Inhibition of proteasome function prevents $I \kappa B$ degradation}

Signal-induced phosphorylation and ubiquitination of $I \kappa B$ and its degradation by the $26 \mathrm{~S}$ proteasome precede N F-KB nuclear translocation. Inhibitors of proteasome function reduce the degradation of $I \kappa B$ to prevent activation of the N F-KB pathway $(1,4)$. A variety of peptide aldehydes, including MG101, MG132, and MG115, make up one class of agents that inhibit the protease activity of the proteasome. Proteasome inhibitors of another class, including lactacystin, block protein degradation activity by acylating a threonine residue in one of the key proteasome subunits. Finally, a group of boronic acid peptides, including PS-341, are extremely potent inhibitors of proteasome function (44). Recently, PS341 has shown promise as an adjunct to cancer chemotherapy by inhibiting activation of the N F- $\mathrm{KB}$ pathway. It is also possible that inhibitors of the ubiquitin ligase that mediates $I \kappa B$ ubiquitination may be a useful target in preventing proteasome degradation of $I \kappa B$. Thus, a variety of potential inhibitors of proteasome function may have a role interrupting the NF- $\mathrm{KB}$ pathway.

\section{Natural products that inhibit the $N \mathrm{~F}=\mathrm{KB}$ pathway} Flavonoids are naturally occurring phenolic compounds, found in plants, that exhibit a variety of biological activities, including suppression of inflammation, cancer chemoprevention, and protection from vascular disease. Several reports suggest that the properties of the flavonoids quercetin, resveratrol, and myricetin may be mediated through downregulation of the NF-KB pathway $(45,46)$. For example, resveratrol, which is found in red wine, can inhibit NF-kB activity and induceapoptosis in transformed cells, which may contribute to the ability of red wine to reduce mortality from coronary heart diseases and certain cancers (46). Resveratrol has strong inhibitory effects on iNOS expression and $\mathrm{NO}$ generation in activated macrophages (45). Treatment of macrophages with this compound blocks LPS-induced phosphorylation and degradation of $I \kappa B \alpha$ to decrease NF-KB D NA binding activity, suggesting that its antiinflammatory effects may be due at least in part to the inhibition of N F-KB-dependent NO synthesis (45). The inhibitory effects of resveratrol and the flavonoid myricetin on activation of the N F-KB pathway correlate with their ability to reducelKK activity (46). Thus several of thebiological activities of flavonoids may be mediated by their inhibition of theNF-KB pathway. 


\section{Therapeutic implications and perspective}

A better understanding of the regulation of the NF- $\mathrm{KB}$ pathway may provide opportunities for the development of new treatments to inhibit prolonged activation of this pathway. As shown in Figure $1, N F-\kappa B$ is an obvious target for new types of treatment to block the inflammatory response in instances where this process becomes chronic or dysregulated. A variety of widely used anti-inflammatory agents inhibit the NF$\kappa B$ pathway, at least in part, as one of their targets. One concern about inhibiting several of these components of the NF-KB pathway is the specificity of such drugs. For example, the proteasome which is responsible for I $\kappa B$ degradation has many other important functions. Thus, inhibition of proteasome activity could potentially cause severe side effects. It may al so not befeasibleto block theN F-KB pathway for prolonged periods, since NF-kB plays an important role in the maintenance of host defense responses. The prolonged expression in the liver of a degradation-resistant I $\mathrm{kB}$ super-repressor protein in transgenic mice indicates that inhibition of NF-KB activity can occur without liver dysfunction, although theanimals weremoresusceptible to bacterial infection (47). However, short term treatment with specific inhibitors of IKK activity might reduce such potential side effects. It is possiblethat specific inhibitors of IKK activity may provide a new class of anti-inflammatory and anticancer agents or of adjunct therapeutics to enhance the efficacy of other cancer therapies (see Baldwin, this Perspective series, ref. 25).

Although themaintenance of appropriatelevels of NF$\kappa B$ activity is a critical factor in achieving normal cellular proliferation, constitutive N F-KB activation is likely involved in the enhanced growth properties seen in a variety of cancers. The potential applications of inhibition of the NF-kB pathway in cancer chemotherapy are in their early stages. However, such approaches offer the promise of enhancing the efficacy of cancer chemotherapy and reducing abnormal cytokineproduction, which may contributeto the growth of certain tumors.

\section{Acknowledgments}

Wethank Sharon Johnson and Alex Herrera for preparation of themanuscript and figures, respectively. This work was supported by grants from the $\mathrm{NIH}$ and the Department of Veterans Affairs.

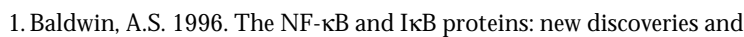
insights. Annu. Rev. Immunol. 14:649-681.

2. Pahl, H.L. 1999. Activators and target genes of Rel/NF-kB transcription factors. Oncogene. 18:6853-6866.

3. Gerondakis, S., Grumont, R., Rourke, I., and Grossmann, M. 1998. The regulation and roles of Rel/NF- $\mathrm{KB}$ transcription factors during lymphocyte activation. Curr. Opin. Immunol. 10:353-359.

4. Ghosh, S., M ay, M.J., and Kopp, E.B. 1998. NF-kB and Rel proteins: evolutionarily conserved mediators of immune responses. Annu. Rev. Immunol. 16:225-260.

5. Barkett, M., and Gilmore, T.D. 1999. Control of apoptosis by Rel/NFkappaB transcription factors. Oncogene. 18:6910-6924.
6. Wang, C.Y., M ayo, M.W., Korneluk, R.G., Goeddel, D.V., and Baldwin, A.S., Jr. 1998. NF-kB anti-apoptosis: induction of TRAF1 and TRAF2 and C-IAP1 and C-IAP2 to suppress caspase- 8 activation. Science. 281:1680-1683.

7. Wu, M.X., Ao, Z., Prasad, K.V., Wu, R., and Schlossman, S.F. 1998. IEX$1 \mathrm{~L}$, an apoptosis inhibitor involved in NF-kB-mediated cell survival. Science. 281:998-1001.

8. Grumont, R.J., Rourke, I.J., and Gerondakis, S. 1998. Rel-dependent induction of $A 1$ transcription is required to protect $B$ cells from antigen receptor ligation-induced apoptosis. Genes D ev. 13:400-411.

9. Wang, C.Y., Guttridge, D.C., M ayo, M.W., and Baldwin, A.S.,Jr. 1999. NF$\kappa B$ induces expression of the $B C l-2$ homologue $A 1 / B f l-1$ to preferentially suppress chemotherapy-induced apoptosis. Mol. Cell. Biol. 19:5923-5929.

10. Guttridge, D.C., Albanese, C., Reuther, J.Y., Pestell, R.G., and Baldwin, A.S., Jr. 1999. NF-кB controls cell growth and differentiation through transcriptional regulation of cyclin D 1. Mol. Cell. Biol. 19:5785-5799.

11. Hinz, M., et al. 1999. N F-kB function in growth control: regulation of cyclin D 1 expression and G0/G1-to-S-phase transition. M ol. Cell. Biol. 19:2690-2698.

12. Tak, P.P., and Firestein, G.S. 2001. NF-кB: a key rolein inflammatory diseases. J. Clin. Invest. 107:7-11.

13. Collins, T., and Cybulsky, M .I. 2001. NF-кB: pivotal mediator or innocent bystander in atherogenesis? J. Clin. Invest. In press.

14. M attson, M .P., and Camandola, S. 2001. NF-kB in neuronal plasticity and neurodegenerative disorders. J. Clin. Invest. In press.

15. Bochner, B.S., Undem, B.J., and Lichtenstein, L.M . 1994. Immunological aspects of allergic asthma. Annu. Rev. Immunol. 12:295-335.

16. Feldmann, M., Brennan, F.M., and M aini, R.N. 1996. Role of cytokines in rheumatoid arthritis. Annu. Rev. Immunol. 14:397-440.

17. Podolsky, D.K. 1991. Inflammatory bowel disease. N. Engl. J. M ed. 325:928-937

18. Ross, R. 1993. The pathogenesis of atherosclerosis: a perspectivefor the 1990s. N ature. 362:801-809.

19. Kaltschmidt, B., Uherek, M., Wellmann, H., Volk, B., and Kaltschmidt, C. 1999. Inhibition of NF-kB potentiates amyloid beta-mediated neuronal apoptosis. Proc. N atl. Acad. Sci. USA. 96:9409-9414.

20. Rayet, B., and Gelinas, C. 1999. Aberrant rel/N F-kB genes and activity in human cancer. Oncogene. 18:6938-6947.

21. Zandi, E., and Karin, M. 1999. Bridging the gap: composition, regulation, and physiological function of thel $\mathrm{\kappa B}$ kinasecomplex. M ol. Cell. Biol. 19:4547-4551.

22. Wang, C.Y., M ayo, M.W., and Baldwin, A.S.J. 1996. TNF- and cancer therapy-induced apoptosis: potentiation by inhibition of NF-KB. Science 274:784-787.

23. Van Antwerp, D.J., M artin, S.J., Kafri, T., Green, D .R., and Verma, I.M 1996. Suppression of TNF- $\alpha$-induced apoptosis by NF-KB. Science 274:787-789.

24. Wang, C.Y., Cusack, J.C., Jr., Liu, R., and Baldwin, A.S., Jr. 1999. Control of inducible chemoresistance: enhanced anti-tumor therapy through increased apoptosis by inhibition of NF-kB. Nat. M ed. 5:412-417.

25. Baldwin, A.S. 2001. Control of apoptosis, oncogenesis, and cancer therapy resistance by the transcription factor NF-KB. J. Clin. Invest. In press.

26. Auphan, N., DiD onato, J.A., Rosette, C., Helmberg, A., and Karin, M. 1995. Immunosuppression by glucocorticoids: inhibition of NF-KB activity through induction of I $\mathrm{KB}$ synthesis. Science. 270:286-290.

27. Scheinman, R.I., Cogswell, P.C., Lofquist, A.K., and Baldwin, A.S., Jr. 1995. Role of transcriptional activation of $1 \kappa B \alpha$ in mediation of immunosuppression by glucocorticoids. Science. 270:283-286.

28. De Bosscher, K., et al. 1997. Glucocorticoid-mediated repression of nuclear factor-kappaB-dependent transcription involves direct interference with transactivation. Proc. N atl. Acad. Sci. USA. 94:13504-13509.

29. Scheinman, R.I., Gual berto, A., Jewell, C.M., Cidlowski, J.A., and Baldwin, A.S, Jr. 1995. Characterization of mechanisms involved in transrepression of N F-кB by activated glucocorticoid receptors. M ol. Cell. Biol. 15:943-953.

30. Sheppard, K.A., et al. 1998. Nuclear integration of glucocorticoid receptor and NF-KB signaling by CREB-binding protein and steroid receptor coactivator-1. J. Biol. Chem. 273:29291-29294.

31. DeBosscher, K., et al. 2000. Glucocorticoids repress N F-kappa B-driven genes by disturbing the interaction of p65 with the basal transcription machinery, irrespective of coactivator levels in the cell. Proc. Natl. Acad. Sci. USA. 97:3919-3924.

32. Vane, J. 1994. Towards a better aspirin. N ature. 367:215-216.

33. Pierce, J.W., Read, M.A., Ding, H., Luscinskas, F.W., and Collins, T. 1996 


\section{NF=KB in defense and disease}

\section{Albert S. Baldwin, Jr, Series Editor}

Salicylates inhibit I $\mathrm{\kappa} \alpha$ phosphorylation, endothelial-leukocyteadhe sion molecule expression, and neutrophil transmigration. J. Immunol. 156:3961-3969.

34. Yin, M.-J., Yamamoto, Y., and Gaynor, R.B. 1998. The anti-inflammatory agents aspirin and salicylate inhibit the activity of I $\mathrm{\kappa B}$ kinase $\beta$. Nature. 396:77-80.

35. Yamamoto, Y., Yin, M .-J., Lin, K.-M ., and Gaynor, R.B. 1999. Sulindac inhibits activation of the NF-KB pathway. J. Biol. Chem. 274:27307-27314.

36. Wahl, C., Liptay, S., Adler, G., and Schmid, R.M . 1997. Sulfasalazine: a potent and specific inhibitor of N F-KB. J. Clin. Invest. 101:1163-1174.

37. Egan, L.J., et al. 1999. Inhibition of interleukin-1-stimulated N F-kappaB RelA/p65 phosphorylation by mesalamine is accompanied by decreased transcriptional activity. J. Biol. Chem. 274:26448-26453.

38. Frantz, B., et al. 1994. Calcineurin acts in synergy with PM A to inactivate $/ \kappa B / M A D 3$, an inhibitor of N F-KB. EM BO J. 13:861-870.

39. M eyer, S., Kohler, N.G., and Joly, A. 1997. Cyclosporine A is a noncompetitiveinhibitor of proteasome activity and prevents N F-KB activation. FEBS Lett. 413:354-358.

40. Marienfeld, R., et al. 1997. Cyclosporin A interferes with the inducible degradation of NF-KB inhibitors, but not with the processing of
p105/N F-kB1 in T cells. Eur. J. Immunol. 27:1601-1609.

41. Venkataraman, L., Burakoff, S. J., and Sen, R. 1995. FK506 inhibits antigen receptor-mediated induction of c-rel in B and T lymphoid cells. J. Exp. Med. 181:1091-1099.

42. Ricote, M., Li, A.C., Willson, T.M., Kelly, C.J., and Glass, C.K. 1998. The peroxisome proliferator-activated receptor-gamma is a negative regulator of macrophage activation. N ature. 391:79-82.

43. Rossi, A., et al. 2000. Anti-inflammatory cyclopentenone prostaglandins are direct inhibitors of I $\mathrm{KB}$ kinase. Nature. 403:103-108.

44. Adams, J., et al. 1999. Proteasome inhibitors: a novel class of potent and effective antitumor agents. Cancer Res. 59:2615-2622.

45. Tsai, S.H., Lin-Shiau, S.Y., and Lin, J.K. 1999. Suppression of nitric oxide synthase and the down-regulation of the activation of N F-KB in macrophages by resveratrol. Br. J. Pharmacol. 126:673-680.

46. Holmes-M cN ary, M ., and Baldwin, A.S., Jr. 2000. Chemopreventive properties of trans-resveratrol are associated with inhibition of activation of the I KB kinase. Cancer Res. 60:3477-3483.

47. Lavon, I., et al. 2000. High susceptibility to bacterial infection, but no liver dysfunction, in mice compromised for hepatocyte N F-KB activation. Nat. M ed. 6:573-577. 